\title{
Pengaruh Motivasi Intrinsik dan Pengetahuan TIK terhadap Kesiapan Digitalisasi UMKM dengan Faktor Demografi sebagai Variabel Pemoderasi (Studi pada UMKM Kuliner di Salatiga)
}

\author{
Rakian Adib Sufi ${ }^{1}$, Lieli Suharti ${ }^{2, *}$ \\ ${ }^{1,2}$ Departemen Manajemen, Fakultas Ekonomika dan Bisnis \\ Universitas Kristen Satya Wacana, Salatiga, Indonesia \\ *Email: lieli.suharti@uksw.edu
}

\begin{abstract}
Digitalization brings many benefits to businesses including culinary SMEs. The benefits include ease of reaching customers digitally, cost efficiency, and being able to expand marketing networks to other regions and even countries. Despite the advantages of digitalization, the majority of MSMEs in Indonesia still have a low level of digitalization readiness. Therefore, this study aims to examine several factors that may affect digitalization readiness, namely intrinsic motivation (X1) and ICT knowledge (X2) as well as demographic moderating $(Z)$ on the digitalization readiness of SMEs. This research is a quantitative research with the number of respondents as many as 90 MSME owners who are determined using accidental sampling technique. The data analysis technique of this research uses Partial Least Square (PLS) with SmartPLS 3.0 software. The results showed that intrinsic motivation and ICT knowledge had a significant positive effect on the digitalization readiness of culinary SMEs in Salatiga City. However, the role of age, education level and gender has not been proven as a moderator of the influence of intrinsic motivation, ICT knowledge of MSME owners on MSME digitalization readiness.
\end{abstract}

\begin{abstract}
Abstraksi: Digitalisasi membawa banyak manfaat untuk bisnis termasuk UMKM kuliner. Manfaat tersebut antara lain kemudahan menjangkau pelanggan secara digital, efisiensi biaya, dan dapat memperluas jaringan marketing ke daerah bahkan negara lain. Terlepas dari kelebihan digitalisasi, mayoritas UMKM di Indonesia masih memiliki tingkat kesiapan digitalisasi yang rendah. Maka dari itu, penelitian ini bertujuan untuk meneliti pengaruh faktor motivasi intrinsik (X1) dan pengetahuan TIK (X2) terhadap kesiapan digitalisasi UMKM. Persoalan penelitian lain yang juga diteliti adalah peran variabel demografi yang mencakup usia, tingkat pendidikan, dan gender sebagai pemoderasi dalam penelitian ini. Penelitian ini merupakan penelitian kuantitatif dengan jumlah responden sebanyak 90 orang pemilik UMKM yang ditentukan menggunakan teknik accidental sampling. Teknik analisis data penelitian ini menggunakan Partial Least Square (PLS) dengan software SmartPLS 3.0. Hasil penelitian menunjukkan bahwa motivasi intrinsik dan pengetahuan TIK berpengaruh positif secara signifikan terhadap kesiapan digitalisasi UMKM kuliner di Kota Salatiga. Namun, dugaan adanya peran faktor usia, tingkat pendidikan, dan gender tidak terbukti sebagai pemoderasi terhadap pengaruh motivasi intrinsik, pengetahuan TIK pemilik UMKM terhadap kesiapan digitalisasi UMKM.
\end{abstract}

Keywords: Digitalization Readiness; Intrinsic Motivation; ICT Knowledge; MSMEs

\section{Pendahuluan}

Digitalisasi merupakan suatu terminologi untuk menjelaskan proses alih teknologi dari yang sebelumnya konvensional (tercetak) menjadi digital (contoh: membuat arsip dokumen bentuk digital, marketplace, $E$ money dan lain-lain). Kehadiran era digital membawa banyak manfaat bagi UMKM. Menurut Sekretaris Kementerian Koperasi dan UKM (Kemenkop UKM) Rully Indrawan ada 3 (tiga) alasan yang mendasari pentingnya digitalisasi UMKM yaitu kemudahan menjangkau pelanggan secara digital, efisiensi biaya (promosi, transportasi, penyimpanan, dan lain lain), dan dapat memperluas jaringan marketing ke daerah bahkan negara lain (Santia, 2020).

Mengingat pentingnya digitalisasi pada UMKM maka perlu diukur tingkat kesiapan UMKM dalam menerima teknologi serta dicari tahu faktor-faktor yang berpengaruh terhadap kesiapan digitalisasi tersebut. Salah satu cara untuk mengukur kesiapan teknologi yaitu dengan menggunakan Technology Readiness Index (TRI). TRI diciptakan oleh Parasuraman pada tahun 2000, yang terdiri 
dari 4 konstruk yaitu optimisme, inovasi, ketidaknyamanan, dan ketidakamanan (R. P. Sari \& Santoso, 2019). Keunggulan dari TRI dibandingkan dengan indikator yang lain adalah lebih jelas, mudah diterapkan, dan menuju langsung kepada diri pemakai teknologi tersebut (Chotijah \& Retrialisca, 2020).

Beberapa penelitian terdahulu telah menggunakan TRI dalam penelitiannya untuk mengetahui tingkat kesiapan teknologi diantaranya Pamukti, Hartanto, \& Winarno (2017); Napitupulu, Syafrullah, Rahim, Abdullah, \& Setiawan (2018); dan Sari dan Santoso (2019). Berdasarkan data mengenai tingkat kesiapan teknologi, saat ini masih banyak UMKM Indonesia yang belum siap menerapkan digitalisasi. Dari 64 juta UMKM Indonesia saat ini, hanya 13 persen atau sebanyak 8 juta UMKM yang sudah hadir di platform digital (Santia, 2020). Hal ini juga didukung oleh penelitian terdahulu yang menemukan bahwa UMKM di beberapa daerah di Indonesia masih menggunakan sistem manual dan jauh dari digitalisasi (Jumadi et al., 2020; Rusliati \& Mulyaningrum, 2019). Selain itu, indeks kesiapan digital di Indonesia, khususnya di Jabodetabek masih berada di taraf menengah yaitu sebesar 3,6 dari point indeks 1-5 (Katadata Insight Center, 2020). Beberapa temuan di atas memberi indikasi bahwa tingkat kesiapan teknologi bagi UMKM di Indonesia belum merata dan cenderung rendah.

Ada berbagai faktor yang menyebabkan rendahnya kesiapan digitalisasi UMKM di Indonesia yang dapat dibagi kedalam faktor eksternal dan faktor internal. Faktor eksternal adalah faktor yang berasal dari luar diri atau dari lingkungan luar, seperti minimnya dukungan dari pemerintah, kurangnya kualitas produk yang dipasarkan sehingga tidak laku di pasaran (Harmawan, 2018), belum memanfaatkan TIK (Napitupulu et al., 2018), dan kurangnya infrastruktur ITC (Slamet et al., 2017). Sementara faktor internal adalah faktor yang berasal dari dalam diri individu UMKM, seperti lebih menyukai pemasaran secara konvensional, kurangnya motivasi berbisnis online, kurang memiliki pengetahuan dalam menjalankan usaha secara online, umur tenaga kerja, dan ketidaksiapan tenaga kerja (Deloitte Access Economic, 2015; Harmawan, 2018; Katadata Insight Center, 2020).

Sejumlah studi terdahulu menunjukkan faktor-faktor internal yang berkaitan erat dengan pemanfaatan teknologi informasi pada UMKM meliputi faktor motivasi intrinsik, pengetahuan TIK, dan faktor demografi. Penelitian Caniëls, Lenaerts, \& Gelderman (2015) menemukan bahwa motivasi intrinsik berpengaruh terhadap niat UMKM dalam menggunakan internet. Sementara itu, penelitian Suhandiah \& Ayuningtyas (2016), menemukan bahwa motivasi intrinsik berpengaruh secara langsung terhadap minat pemanfaatan teknologi.

Terkait dengan pengaruh pengetahuan TIK terhadap kesiapan digitalisasi UKM, menurut Nair, Chellasamy, dan Singh (2019), pengetahuan tentang TIK mempengaruhi inovasi dari usaha UMKM. Menurut mereka, pengetahuan TIK pemilik UKM berpengaruh terhadap organizational IT readiness. Okundaye, Fan, dan Dwyer (2019) menyatakan bahwa perbedaan pengetahuan TIK mempengaruhi adopsi teknologi pada UKM di negara berkembang.

Hal lainnya yang diduga berpengaruh terhadap kesiapan digitalisasi UMKM adalah faktor demografi yang meliputi usia, pendapatan, jenis kelamin, tingkat pendidikan, dan lain-lain. Menurut Nasir (2013), jenis kelamin, umur, dan jenjang pendidikan memberikan moderating effect terhadap penggunaan suatu sistem informasi. Penelitian Talebian, Mohammadi, dan Rezvanfar (2014) menemukan bahwa tingkat pendidikan dapat meningkatkan pemahaman penggunaan teknologi yang lebih baik. Sementara Okundaye, Fan, dan Dwyer (2019) dalam penelitiannya menemukan bahwa pendidikan yang buruk merupakan salah satu hambatan dan kendala dalam adopsi digital di negara berkembang.

Faktor usia juga diduga berpengaruh terhadap kesiapan teknologi karena dapat mempengaruhi keempat indikator TRI. Menurut penelitian dari Katadata Insight Center (2020), generasi yang lebih tua (di atas 40 tahun) terbukti memiliki kesiapan teknologi yang lebih rendah dari generasi yang lebih muda. Hal serupa juga didukung 
oleh penelitian Pramana dan Mandala (2014) yang mengatakan bahwa pada generasi yang lebih tua, akan memperlemah hubungan optimisme dan inovatif (studi kasus pada layanan online banking). Selanjutnya, faktor gender juga diduga berpengaruh terhadap kesiapan digitalisasi UMKM (Nasir, 2013). Zhang, Nyheim, dan Mattila (2017) dalam penelitiannya menemukan bahwa laki-laki memiliki computer self-efficacy yang lebih tinggi dari perempuan.

UMKM kuliner merupakan UMKM yang banyak terdapat di berbagai daerah di Indonesia. Dalam masa pandemi Covid-19, UMKM kuliner banyak terdampak karena pemberlakuan pembatasan sosial yang mengharuskan masyarakat untuk tinggal di rumah dan menjaga jarak. Usaha kuliner dapat bertahan apabila mereka dapat mengubah cara pemasaran konvensional ke cara pemasaran online. Penelitian ini akan berfokus pada UMKM kuliner di Kota Salatiga.

Berdasarkan latar belakang tersebut di atas, maka penelitian ini mengangkat permasalahan tentang pengaruh motivasi intrinsik dan pengetahuan TIK terhadap kesiapan digitalisasi UMKM dengan faktor demografi sebagai pemoderasi, studi terhadap UMKM kuliner di Kota Salatiga. Adapun persoalan penelitian dari penelitian ini adalah sebagai berikut: (1) Apakah motivasi intrinsik berpengaruh terhadap kesiapan digitalisasi UMKM kuliner di Salatiga?; (2) Apakah pengetahuan TIK berpengaruh terhadap kesiapan digitalisasi UMKM kuliner di Salatiga?; dan (3) Apakah tingkat pendidikan, usia, dan gender memoderasi pengaruh motivasi intrinsik dan pengetahuan TIK terhadap kesiapan digitalisasi?

\section{Tinjauan Pustaka}

\section{Kesiapan Digitalisasi}

Kesiapan digital pada penelitian ini merujuk pada definisi e-readiness sebagai kemampuan perusahaan atau unit organisasi untuk menjadi siap, bersedia untuk mengadopsi, menggunakan, dan mendapatkan manfaat dari e-inovasi (Y. K. P. Sari, 2018; Septikhtiarif \& Handayaningsih, 2017). TRI atau Technology Readiness Index diciptakan oleh parasuraman pada tahun 2000. TRI terdiri dari 4 konstruk yaitu optimisme, inovasi, ketidaknyamanan, dan ketidakamanan (R. P. Sari \& Santoso, 2019). Dari 4 indikator tersebut optimisme dan inovasi merupakan dimensi yang paling penting dalam pengadopsian produk yang berbasis teknologi. Menurut Pramana \& Mandala (2014), semakin tinggi tingkat optimisme dan inovasi untuk menggunakan produk berbasis teknologi akan semakin tinggi pula niat/kesiapan untuk menuju digitalisasi.

\section{Motivasi Intrinsik}

Menurut Embi \& Saili (2013), motivasi memiliki arti yang sama dengan motif yaitu daya pendorong atau perangsang kepada seseorang untuk mengamalkan sesuatu perbuatan. Dalam teori motivasi, Linawati (2014) membagi motivasi menjadi 2 (dua) yaitu motivasi intrinsik dan motivasi ekstrinsik. Menurut Putra \& Frianto (2013), motivasi intrinsik adalah pendorong kerja yang bersumber dari dalam diri individu berupa kesadaran mengenai pentingnya atau manfaat atau makna pekerjaan yang dilaksanakan. Sumber referensi lain yaitu Sonora (2019), menyatakan bahwa motivasi intrinsik adalah motivasi yang berasal dari dalam diri untuk seseorang dalam melakukan suatu perbuatan untuk mencapai tujuan. Dari definisi tersebut, dapat dikatakan bahwa motivasi intrinsik merupakan dorongan dari dalam diri individu untuk mencapai tujuan. Motivasi intrinsik memiliki indikator yang meliputi beberapa faktor, yaitu pengakuan, pencapaian, kemungkinan untuk tumbuh, kemungkinan untuk maju, dan pekerjaan itu sendiri. Sementara menurut Maulana, Hamid, \& Mayoan (2015), beberapa faktor dari motivasi intrinsik, yaitu: tanggung jawab, penghargaan, pekerjaan itu sendiri, dan pengembangan serta kemajuan.

\section{Pengetahuan TIK}

Pengetahuan Teknologi Informasi Komunikasi (TIK) dapat diartikan sebagai segala sesuatu yang diketahui individu mengenai jalur komunikasi kecepatan tinggi yang membawa data, suara, dan video (A. S. Putri, 2020; K. Putri, 2018). Sementara, menurut Putri (2020), TIK dapat diartikan teknologi yang berhubungan dengan pengambilan, pengumpulan, pengolahan, 
penyimpanan, penyebaran, dan penyajian informasi. Dengan demikian, pengetahuan TIK dapat diartikan sebagai segala sesuatu yang diketahui individu mengenai jalur komunikasi kecepatan tinggi yang membawa data, suara, dan video. Saat ini, jalur komunikasi kecepatan tinggi sudah terhubung ke internet sehingga data, suara, dan video disajikan dengan serba digital. Pengetahuan TIK memiliki beberapa faktor, diantaranya dukungan TIK dan penggunaan TIK (Widiastuti \& Budi, 2016). Dengan memadainya dukungan TIK dan intensitas penggunaannya yang semakin banyak dapat meningkatkan pengetahuan individu tentang TIK yang berujung pada meningkatnya kesiapan teknologi.

\section{Pengembangan Hipotesis Penelitian Pengaruh Motivasi Intrinsik terhadap Kesiapan Digital UMKM}

Motivasi intrinsik seperti yang dijelaskan sebelumnya merupakan dorongan yang berasal dari dalam diri untuk mencapai tujuan (Putra \& Frianto, 2013; Sonora.id, 2019). Salah satu faktor dari motivasi intrinsik yang disampaikan dalam Maulana et al. (2015) adalah pengembangan dan kemajuan. Semakin tinggi motivasi intrinsik UMKM maka semakin tinggi pula keinginannya untuk maju dan berkembang, bila keinginan untuk maju dan berkembangnya tinggi maka dapat dikatakan kesiapannya untuk menerima teknologi atau digitalisasi juga semakin tinggi. Pendapat tersebut didukung oleh penelitian Caniëls et al. (2015) dan Suhandiah \& Ayuningtyas (2016) yang menyimpulkan bahwa motivasi intrinsik berpengaruh terhadap minat penggunaan teknologi. Selanjutnya, semakin tinggi faktor optimisme dan keinovatifan dalam TRI, akan meningkatkan niat dalam penggunaan teknologi digital (Pramana \& Mandala, 2014). Berdasarkan pemaparan di atas, dapat dirumuskan hipotesis penelitian sebagai berikut:

$\mathrm{H} 1$ = motivasi intrinsik berpengaruh positif terhadap kesiapan digitalisasi UMKM

Pengaruh Pengetahuan TIK terhadap Kesiapan Digital UMKM

Pengetahuan TIK diduga dapat mempengaruhi kesiapan digitalisasi UMKM. Menurut Nair et al. (2019), pengetahuan pemilik UMKM tentang TIK berpengaruh terhadap inovasi usaha. Nair et al. (2019) dalam penelitiannya membuktikan bahwa pengetahuan TIK pemilik UKM berpengaruh signifikan terhadap organizational IT readiness yang artinya dengan meningkatnya pengetahuan TIK dapat meningkatkan kesiapan IT organisasi. Sementara, Okundaye et al. (2019) menemukan bahwa pengetahuan

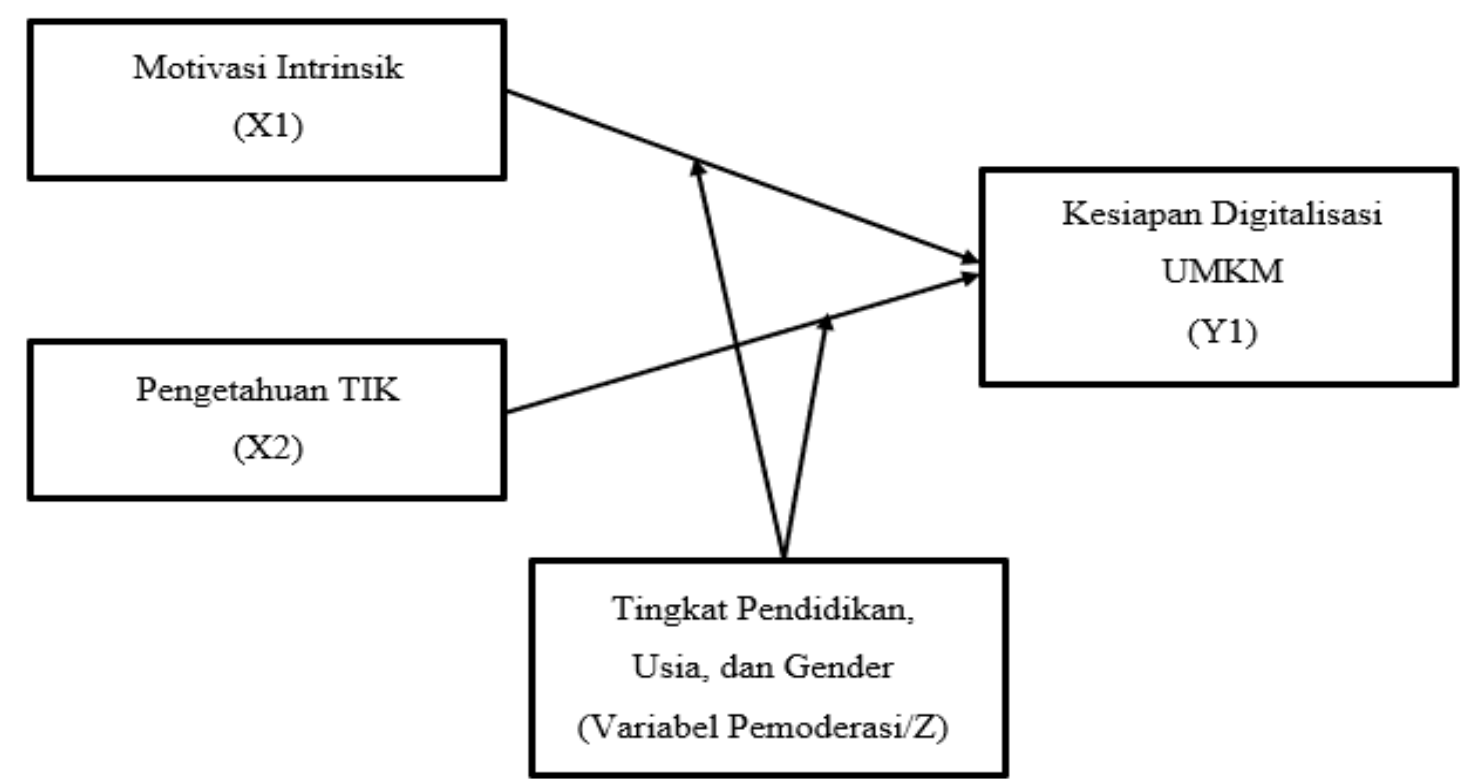

\section{Gambar 1. Model Penelitian}


TIK mempengaruhi adopsi teknologi pada UKM di negara berkembang. Rendahnya dukungan TIK serta penggunaan TIK akan menyebabkan rendahnya kesiapan digital, demikian juga sebaliknya jika pengetahuan TIK UMKM tinggi, maka UMKM akan lebih siap menjadi E-UMKM (Napitupulu et al., 2018; Slamet et al., 2017). Dengan demikian, berdasarkan dukungan literatur di atas, maka dirumuskan hipotesis penelitian berikut:

$\mathrm{H} 2$ = pengetahuan TIK berpengaruh positif terhadap kesiapan digitalisasi UMKM

Tingkat Pendidikan, Usia, dan Gender sebagai Variabel Pemoderasi

Tingkat pendidikan, usia, dan gender diduga ikut berperan terhadap kesiapan digitalisasi UMKM. Hal ini didasari pada pernyataan Nasir (2013), bahwa jenis kelamin, umur, dan pengalaman dari pendidikan dapat memperkuat dorongan terhadap penggunaan suatu sistem informasi.
Perbedaan pendidikan menentukan perbedaan perilaku individu dalam memperlakukan teknologi, sehingga semakin tinggi tingkat pendidikan, maka semakin baik perilaku individu dalam menggunakan teknologi (Okundaye et al., 2019; Talebian et al., 2014).

Usia berpengaruh erat terhadap kesiapan teknologi. Menurut penelitian dari Katadata Insight Center (2020), generasi yang lebih tua terbukti memiliki kesiapan teknologi yang lebih rendah dari generasi yang lebih muda. Pramana \& Mandala (2014) telah membuktikan dalam penelitiannya bahwa semakin tinggi usia maka semakin rendah optimisme dan inovatif dalam menggunakan teknologi tersebut. Terkait dengan gender, Zhang et al. (2017) dalam penelitiannya menemukan bahwa laki-laki memiliki computer self-efficacy yang lebih tinggi dari perempuan, sehingga diperkirakan pemilik UMKM bergender laki-laki akan lebih siap melakukan digitalisasi usaha mereka.

Tabel 1. Definisi Konsep \& Indikator

\begin{tabular}{|c|c|c|c|}
\hline Variabel dan Definisi & & Dimensi & Indikator \\
\hline \multirow{2}{*}{$\begin{array}{l}\text { Motivasi Intrinsik } \\
\text { Linawati (2014), } \\
\text { diolah }\end{array}$} & \multirow{2}{*}{$\begin{array}{l}\text { Dorongan dari } \\
\text { dalam diri } \\
\text { individu untuk } \\
\text { mencapai tujuan }\end{array}$} & $\begin{array}{l}\text { Kemungkinan } \\
\text { untuk tumbuh }\end{array}$ & $\begin{array}{l}\text { Keinginan pemilik usaha untuk } \\
\text { memperluas bisnisnya }\end{array}$ \\
\hline & & $\begin{array}{l}\text { Kemungkinan } \\
\text { untuk maju }\end{array}$ & $\begin{array}{l}\text { Kepuasan/ ketidakpuasan pemilik usaha } \\
\text { terhadap kondisinya saat ini sehingga } \\
\text { menimbulkan rasa ingin berubah/maju ke } \\
\text { arah yang lebih baik }\end{array}$ \\
\hline \multirow{2}{*}{$\begin{array}{l}\text { Pengetahuan TIK } \\
\text { Widiastuti \& Budi } \\
\text { (2016), diolah }\end{array}$} & \multirow{2}{*}{$\begin{array}{l}\text { Segala sesuatu } \\
\text { yang diketahui } \\
\text { individu } \\
\text { mengenai } \\
\text { teknologi } \\
\text { informasi dan } \\
\text { komunikasi } \\
\end{array}$} & $\begin{array}{l}\text { Penggunaan } \\
\text { TIK }\end{array}$ & $\begin{array}{l}\text { Kemampuan pemilik usaha dalam } \\
\text { mengoperasikan software/ teknologi untuk } \\
\text { menunjang bisnisnya }\end{array}$ \\
\hline & & Dukungan TIK & $\begin{array}{l}\text { Infrastruktur TIK yang tersedia di } \\
\text { lingkungan atau yang dimiliki oleh pemilik } \\
\text { usaha }\end{array}$ \\
\hline \multirow{3}{*}{$\begin{array}{l}\text { Demografi } \\
\text { Nasir (2013), diolah }\end{array}$} & \multirow{3}{*}{$\begin{array}{l}\text { Ilmu yang } \\
\text { mempelajari } \\
\text { dinamika } \\
\text { kependudukan } \\
\text { manusia }\end{array}$} & $\begin{array}{l}\text { Tingkat } \\
\text { pendidikan }\end{array}$ & \\
\hline & & Usia & \\
\hline & & Gender & \\
\hline $\begin{array}{l}\text { Kesiapan Digitalisasi } \\
\text { UMKM }\end{array}$ & $\begin{array}{l}\text { Kemampuan } \\
\text { UMKM untuk } \\
\text { menjadi siap, }\end{array}$ & Optimisme & $\begin{array}{l}\text { Pandangan positif pemilik usaha mengenai } \\
\text { TIK yang ditinjau dari manfaat TIK dalam } \\
\text { kehidupan/ bisnisnya }\end{array}$ \\
\hline $\begin{array}{l}\text { Parasuraman \& } \\
\text { Colby (2015) dan } \\
\text { Pramana \& Mandala } \\
\text { (2014), diolah }\end{array}$ & $\begin{array}{l}\text { bersedia untuk } \\
\text { mengadopsi, } \\
\text { menggunakan, } \\
\text { dan mendapatkan } \\
\text { manfaat dari e- } \\
\text { inovasi }\end{array}$ & Keinovatifan & $\begin{array}{l}\text { Pandangan pemilik usaha terhadap dirinya } \\
\text { sendiri dalam keinovatifan teknologi }\end{array}$ \\
\hline
\end{tabular}


Berdasarkan pemaparan di atas, dirumuskan hipotesis berikut:

$\mathrm{H} 3$ = tingkat pendidikan, usia, dan gender berperan sebagai pemoderasi pengaruh motivasi intrinsik terhadap kesiapan digitalisasi UMKM

H4 = tingkat pendidikan, usia, dan gender berperan sebagai pemoderasi pengaruh pengetahuan TIK terhadap kesiapan digital UMKM

\section{Metode Penelitian}

Penelitian ini merupakan penelitian kuantitatif dan data akan diolah dengan menggunakan analisis statistik guna menguji pengaruh variabel independen yaitu motivasi intrinsik dan pengetahuan TIK terhadap kesiapan digitalisasi UMKM dengan faktor demografi sebagai variabel pemoderasi. Populasi penelitian ini adalah pemilik UMKM kuliner yang ada di Kota Salatiga, Jawa Tengah yang telah memiliki bangunan tempat berjualan yang pasti (milik sendiri/sewa). Populasi sampel tidak diketahui, karena data sekunder tentang jumlah UMKM kuliner yang terdapat di Kota Salatiga tidak tersedia di data
BPS Kota Salatiga maupun data di Kantor Dinas Koperasi dan UKM Kota Salatiga. Oleh karena itu, dalam menentukan jumlah sampel dalam penelitian ini, digunakan teknik penarikan sampel dengan menggunakan accidental sampling. Selanjutnya, sampel pada penelitian ini berjumlah 90 sesuai dengan saran Roscoe (dalam Sekaran dan Bougie, 2016) bahwa untuk populasi tidak diketahui, maka jumlah sampel dikali 10 dengan jumlah dimensi yang ada.

Teknik pengumpulan data dalam penelitian ini menggunakan kuesioner terstruktur. Persebaran kuesioner dilakukan secara tidak langsung menggunakan google form yang didistribusikan melalui email dan sosial media. Namun, distribusi kuesioner ada juga yang dilakukan secara langsung dengan mengunjungi UMKM kuliner yang bersedia berpartisipasi. Beberapa variabel yang diteliti meliputi motivasi intrinsik, pengetahuan TIK, kesiapan digital dan faktor demografi. Skala yang digunakan untuk mengukur setiap indikator menggunakan skala ordinal dengan nilai 1 sampai 5 (1=sangat tidak setuju; $5=$ sangat setuju). Khusus untuk variabel

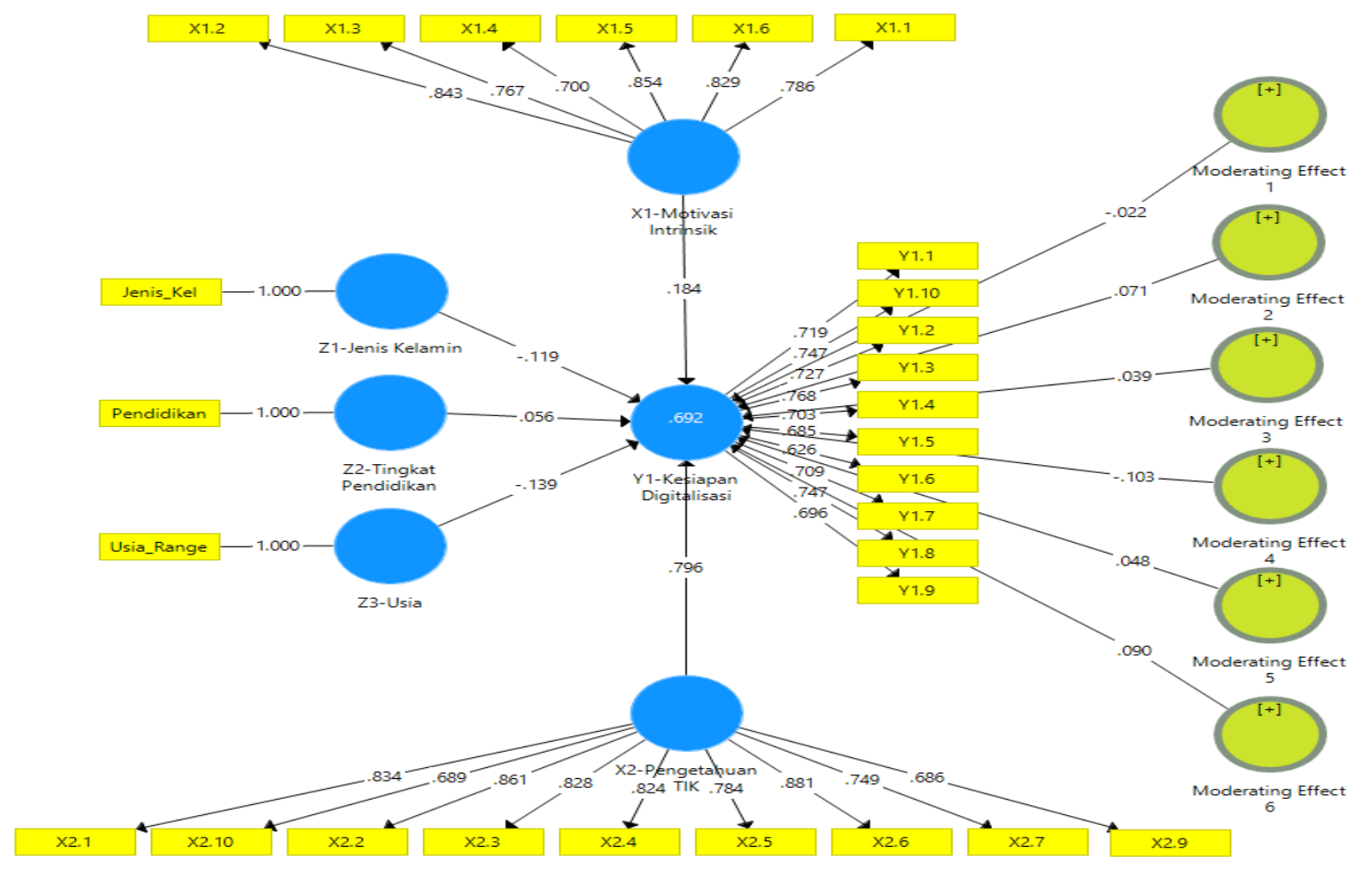

Gambar 2. Model kedua 
gender diukur dengan skala nominal, dan variabel umur dengan skala rasio.

\section{Teknik Analisis Data}

Teknik analisis data menggunakan analisis statistik inferensia PLS-SEM dengan software SmartPLS 3.0. PLS memiliki dua spesifikasi model, yaitu outer model (model pengukuran) dan inner model (model struktural). Outer model digunakan untuk menguji validitas dan reliabilitas konstruk, melihat hubungan antar konstruk (analisis jalur) dan merumuskan hipotesis.

Tabel 2. Kriteria Outer Model

\begin{tabular}{|c|c|}
\hline Evaluasi & Kriteria \\
\hline $\begin{array}{l}\text { Convergent } \\
\text { Validity }\end{array}$ & $\begin{array}{l}\text { Outer Loading } \geq 0,70 \text { atau } \\
\text { untuk penelitian tahap awal } \\
\text { nilai } \leq 0,70(0,50-0,60) \text { masih } \\
\text { dapat diterima. }\end{array}$ \\
\hline $\begin{array}{l}\text { Discriminant } \\
\text { Validity }\end{array}$ & $\begin{array}{l}\text { Nilai cross loading indikator } \\
\text { yang berkorelasi dengan } \\
\text { dirinya sendiri lebih tinggi dari } \\
\text { korelasi dengan indikator lain }\end{array}$ \\
\hline AVE & $\begin{array}{lcr}\text { Nilai } & \text { Akar AVE }> & \text { korelasi } \\
\text { antar } & \text { konstruk } & \text { atau } \\
\text { direkomendasikan } \geq 0,50 & \\
\end{array}$ \\
\hline Reliabilitas & $\begin{array}{l}\text { Cronbach's Alpha } \geq 0,70 \text { dan } \\
\text { Composite Reliability } \geq 0,70\end{array}$ \\
\hline \multicolumn{2}{|c|}{ Sumber: Riyanto and Hatmawan (2020) } \\
\hline $\begin{array}{l}\text { Menurut } \\
\text { outer model } \mathrm{d} \\
\text { yaitu: valic }\end{array}$ & $\begin{array}{l}\text { iyanto and Hatmawan (2020) } \\
\text { gi ke dalam beberapa kriteria } \\
\text { as konvergen, validita }\end{array}$ \\
\hline
\end{tabular}

agar kriteria tersebut terpenuhi dipaparkan dalam Tabel 2.

Sementara itu, inner model ditunjukkan dengan nilai $R$-square untuk konstruk dependen, Stone-Geisser Q-square test untuk predictive relevance, uji $\mathrm{T}$ dan $P$-value dengan path coefficients untuk mengetahui pengaruh dari variabel-variabel dalam penelitian. Cara mengetahuinya adalah dengan membandingkan $\mathrm{T}$ statistik dan $P$ value dalam data dengan $\mathrm{T}$ tabel dan signifikansi $P$-value yang ingin diteliti $(0,05$ atau 0,1 ).

\section{Hasil dan Pembahasan}

\section{Pengukuran Bagian Luar (Outer Model)}

Pengukuran outer model dilihat melalui pengukuran tiga kriteria, yaitu: validitas konvergen, validitas diskriminan, dan composite reliability. Berdasarkan uji PLS Algorithm untuk model pertama didapatkan nilai outer loading yang belum sesuai dengan rule of thumb yaitu memiliki outer loading di atas 0,70 (Sofyani, 2016). Oleh karena itu, bagian konstruk variabel yang tidak valid pada model pertama yang memiliki nilai outer loading di bawah 0,70 dikeluarkan dalam pengujian (Riyanto \& Hatmawan, 2020; Sofyani, 2016).

Setelah semua konstruk variabel X1 (motivasi intrinsik) yang memiliki nilai dibawah rule of thumb 0,70 dikeluarkan maka model penelitian kedua menjadi seperti yang

Tabel 3. Reliabilitas dan Validitas Model Kedua

\begin{tabular}{|c|c|c|c|c|}
\hline & $\begin{array}{l}\text { Cronbach's } \\
\text { Alpha }\end{array}$ & rho_A & $\begin{array}{l}\text { Composite } \\
\text { Reliability }\end{array}$ & $\begin{array}{l}\text { Average Variance } \\
\text { Extracted }(A V E)\end{array}$ \\
\hline Moderating Effect 1 & 1,000 & 1,000 & 1,000 & 1,000 \\
\hline Moderating Effect 2 & 1,000 & 1,000 & 1,000 & 1,000 \\
\hline Moderating Effect 3 & 1,000 & 1,000 & 1,000 & 1,000 \\
\hline Moderating Effect 4 & 1,000 & 1,000 & 1,000 & 1,000 \\
\hline Moderating Effect 5 & 1,000 & 1,000 & 1,000 & 1,000 \\
\hline Moderating Effect 6 & 1,000 & 1,000 & 1,000 & 1,000 \\
\hline X1-Motivasi Intrinsik &, 887 & ,903 & ,913 & ,637 \\
\hline X2-Pengetahuan TIK & ,926 & ,928 & ,939 & ,633 \\
\hline Y1-Kesiapan Digitalisasi & ,892 & ,894 & ,912 & ,509 \\
\hline Z1-Jenis Kelamin & 1,000 & 1,000 & 1,000 & 1,000 \\
\hline Z2-Tingkat Pendidikan & 1,000 & 1,000 & 1,000 & 1,000 \\
\hline Z3-Usia & 1,000 & 1,000 & 1,000 & 1,000 \\
\hline
\end{tabular}


diperlihatkan pada gambar 2. Selanjutnya, di uji konstruk reliabilitas dan validitas yang memperlihatkan nilai AVE.

Dari masing-masing variabel di atas 0,50 yang berarti memenuhi syarat validitas konvergen dan dapat dilakukan uji lainnya. Berdasarkan hasil analisis statistik, outer model penelitian ini terbukti memenuhi syarat validitas konvergen, validitas diskriminan, dan composite reliability, sehingga dengan lolosnya uji outer model maka dapat dilakukan uji inner model.

\section{Pengukuran Bagian Dalam (Inner Model)}

Pengukuran inner model atau model struktural bertujuan untuk mengukur hubungan antar variabel independen dan variabel dependen laten (Riyanto \& Hatmawan, 2020). Ada beberapa ukuran yang bisa digunakan dalam SmartPLS 3.0 untuk menguji model struktural.

Pengujian ini dilakukan untuk mengetahui kekuatan prediksi dari model struktural. Dalam SmartPLS, nilai tersebut dapat dilihat melalui $R$-square yang terdapat pada variabel endogen (dependen). Kekuatan prediksi dapat dilihat dengan menggunakan kriteria $R$-square 0,67 kuat; 0,33 moderat; 0,19 lemah (Riyanto \& Hatmawan, 2020; Syarifah, Mawardi, \& Iqbal, 2020). Sementara $Q$-square dapat mengukur seberapa baik nilai observasi yang dihasilkan oleh model dan juga estimasi parameternya. Nilai $Q$-square lebih besar dari 0 (nol) menunjukkan bahwa model mempunyai prediktif relevan, sedangkan apabila nilai $Q$-square kurang dari 0 (nol) menunjukkan bahwa model kurang mempunyai prediktif relevan.

\section{Analisis Jalur (Path Coefficients)}

Dalam pengujian jalur ada 2 syarat yang harus terpenuhi, yakni $P$-value data $\leq P$-value signifikansi yang ingin diteliti $(0,05$ atau 0,1$)$ dan $\mathrm{T}$ statistik $\geq \mathrm{T}$ tabel (berdasarkan perhitungan d.f. ditemukan d.f. sebesar 91, maka $\mathrm{T}$ tabel $=1,986$ untuk tingkat kesalahan 5 persen two-tailed dan T tabel $=1,662$ untuk tingkat kesalahan 10 persen two-tailed). Tanpa adanya kedua syarat ini maka hipotesis dalam penelitian ini dianggap tidak terbukti (Riyanto \& Hatmawan, 2020; Sofyani, 2016). Pada tabel 4 diperlihatkan bahwa hubungan antar variabel motivasi intrinsik terhadap kesiapan digitalisasi UMKM memenuhi syarat analisis jalur dengan tingkat

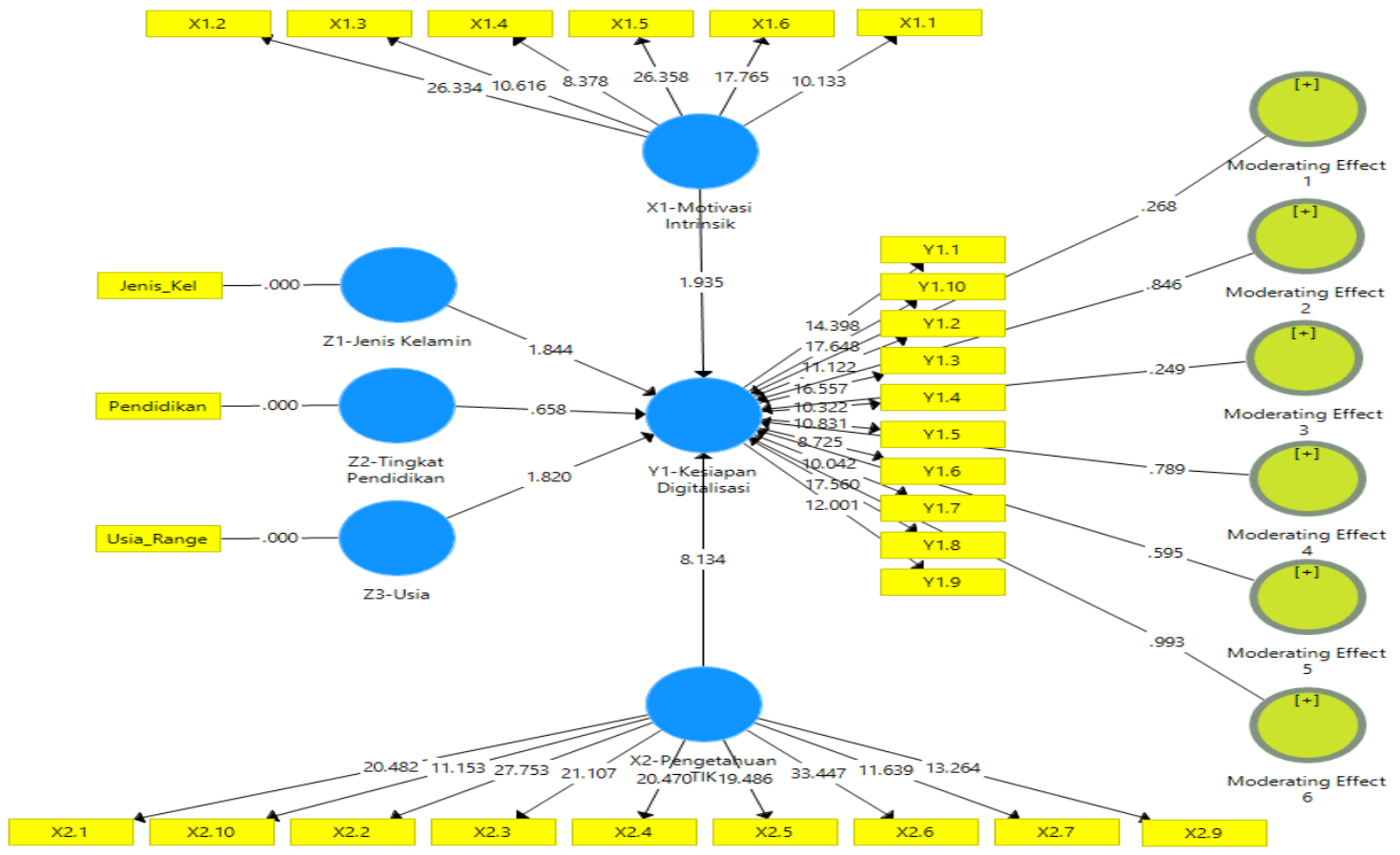

Gambar 3. Inner model 
kepercayaan 90 persen. Sementara, hubungan variabel pengetahuan TIK terhadap kesiapan digitalisasi UMKM berdasarkan analisis jalur memenuhi syarat dengan tingkat kepercayaan 95 persen. Serta sisanya yaitu moderating effect 1 sampai moderating effect 6 (yang mempengaruhi variabel dependen kesiapan digitalisasi (Y1) dalam penelitian ini adalah sebesar 69,2 persen dan sisanya (30,8 persen) dipengaruhi oleh variabel lain diluar penelitian ini.

Tabel 4. Analisis Jalur

\begin{tabular}{|c|c|c|c|c|c|}
\hline & $\begin{array}{l}\text { Original } \\
\text { Sample } \\
(\text { O) }\end{array}$ & $\begin{array}{l}\text { Sample } \\
\text { Mean } \\
(M)\end{array}$ & $\begin{array}{l}\text { Standard } \\
\text { Deviation } \\
\text { (STDEV) }\end{array}$ & $\begin{array}{l}T \quad \text { Statistics } \\
(|O / S T D E V|)\end{array}$ & P-values \\
\hline $\begin{array}{l}\text { Moderating Effect } 1 \text { (X1-Z1) } \\
->\text { Y1-Kesiapan Digitalisasi }\end{array}$ &,- 022 &,- 046 & ,081 & ,268 & ,789 \\
\hline $\begin{array}{l}\text { Moderating Effect } 2 \text { (X2-Z1) } \\
->\text { Y1-Kesiapan Digitalisasi }\end{array}$ & ,071 & ,084 & ,084 & ,846 & ,398 \\
\hline $\begin{array}{lr}\text { Moderating } & \text { Effect 3 (X1- } \\
\text { Z2)-> } & \text { Y1-Kesiapan } \\
\text { Digitalisasi } & \end{array}$ & ,039 & ,073 & , 155 & ,249 & ,804 \\
\hline $\begin{array}{lr}\text { Moderating } & \text { Effect } 4 \text { (X2- } \\
\text { Z2)-> } & \text { Y1-Kesiapan } \\
\text { Digitalisasi } & \\
\end{array}$ &,- 103 &,- 141 & ,131 & ,789 & ,431 \\
\hline $\begin{array}{lr}\text { Moderating } & \text { Effect 5 (X1- } \\
\text { Z3)-> } & \text { Y1-Kesiapan } \\
\text { Digitalisasi } & \\
\end{array}$ & ,048 &, 050 & ,081 & ,595 & ,552 \\
\hline $\begin{array}{lr}\text { Moderating } & \text { Effect } 6 \text { (X2- } \\
\text { Z3)-> } & \text { Y1-Kesiapan } \\
\text { Digitalisasi } & \\
\end{array}$ & ,090 & ,074 & ,091 & ,993 & ,321 \\
\hline $\begin{array}{l}\text { X1-Motivasi Intrinsik -> Y1- } \\
\text { Kesiapan Digitalisasi }\end{array}$ & ,184 & ,217 & ,095 & 1,935 & ,054 \\
\hline $\begin{array}{l}\text { X2-Pengetahuan TIK -> Y1- } \\
\text { Kesiapan Digitalisasi }\end{array}$ & ,796 &, 780 & ,098 & 8,134 & ,000 \\
\hline $\begin{array}{l}\text { Z1-Jenis Kelamin } \quad->\quad Y 1- \\
\text { Kesiapan Digitalisasi }\end{array}$ &,- 119 &,- 118 & ,065 & 1,844 & ,066 \\
\hline $\begin{array}{l}\text { Z2-Tingkat Pendidikan -> } \\
\text { Y1-Kesiapan Digitalisasi }\end{array}$ & ,056 & ,073 & ,086 & ,658 & ,511 \\
\hline $\begin{array}{lll}\text { Z3-Usia } \rightarrow & \text { Y1-Kesiapan } \\
\text { Digitalisasi } & \end{array}$ &,- 139 &,- 135 & ,076 & 1,820 & ,069 \\
\hline
\end{tabular}

merupakan hasil variabel pemoderasi dengan hubungan motivasi intrinsik dan pengetahuan TIK terhadap kesiapan digitalisasi) melalui tabel 4 tidak memenuhi syarat analisis jalur.

$R$-square (R2) dan $Q$-square (Q2)

$R$-square merupakan nilai yang digunakan untuk mengetahui kekuatan prediksi dari model struktural. Kekuatan prediksi dapat dilihat dengan menggunakan kriteria $R$-square 0,67 kuat; 0,33 moderat; 0,19 lemah. Hasil penelitian ini menunjukkan bahwa nilai $R$-square yang didapat sebesar 0,692 yang berarti kemampuan prediksi berada dalam kriteria kuat.

Selanjutnya nilai $R$-square sebesar 0,692 yang didapat juga menjelaskan bahwa kemampuan variabel independen dalam
Sedangkan untuk $Q$-square memiliki perhitungan [1-(1- R Square $\left.\left.{ }^{2}\right)=0,479\right]$. Dari hasil tersebut, terbukti bahwa nilai $\mathrm{Q} 2 \geq 0$ yaitu 0,479 , artinya model ini memiliki prediktif relevan (Riyanto \& Hatmawan, 2020; Syarifah et al., 2020). Dari nilai tersebut, besarnya keragaman data dari penelitian yang dapat dijelaskan oleh model struktural yang dirancang adalah sebesar 47,9 persen, sedangkan sisanya 52,1 persen dijelaskan oleh faktor lain diluar model.

\section{Pembahasan}

Pengaruh Motivasi Intrinsik terhadap Kesiapan Digitalisasi UMKM

Berdasarkan hasil analisis statistik, motivasi intrinsik memiliki pengaruh yang 
positif terhadap kesiapan digitalisasi UMKM dengan tingkat kepercayaan 90 persen. Hal tersebut dinyatakan dengan nilai $\mathrm{T}$ statistik $\geq$ T tabel $(1,662)$ dan nilai $P$-value $\leq 0,10$. Selanjutnya, original sampel pada hubungan antar variabel motivasi intrinsik dan kesiapan digital menunjukkan nilai 0,184 , sehingga berdasarkan pengujian statistik tersebut menunjukkan bahwa motivasi intrinsik memiliki pengaruh yang positif terhadap kesiapan digitalisasi UMKM.

Hasil penelitian ini menunjukkan bahwa motivasi intrinsik berpengaruh secara langsung terhadap kesiapan digitalisasi UMKM di Kota Salatiga. Artinya bahwa variabel motivasi intrinsik ditingkatkan sebesar satu kali, maka kesiapan digitalisasi

UMKM di Kota Salatiga akan meningkat sebesar 18,4 persen. Pengaruh positif tersebut dikarenakan adanya dorongan dari dalam diri pemilik UMKM untuk terus maju dan menumbuhkan usahanya. Semakin tinggi keinginan pemilik UMKM untuk terus memajukan usahanya maka semakin tinggi pula keinginannya untuk bisa beradaptasi dengan perkembangan teknologi yang ada saat ini. Semakin tinggi motivasi pemilik UMKM dalam menumbuhkan dan mengembangkan bisnisnya maka ia akan semakin termotivasi untuk meningkatkan SDM nya karena diperlukan SDM yang semakin memadai untuk hal tersebut. Salah satu aspek yang memadai adalah pengetahuan memanfaatkan digitalisasi (online marketing) untuk meningkatkan luas cangkupan usaha dan penjualannya agar bisnisnya semakin berkembang.

Maka, berdasarkan dari pernyataanpernyataan tersebut di atas hasil riset ini mendukung serta melengkapi penelitian terdahulu yang dilakukan oleh Caniëls, Lenaerts, \& Gelderman (2015) dan Suhandiah \& Ayuningtyas (2016) yang mengemukakan bahwa motivasi intrinsik berpengaruh terhadap minat penggunaan teknologi. Hasil penelitian ini membuktikan bahwa variabel motivasi intrinsik berpengaruh positif terhadap variabel kesiapan digitalisasi UMKM, sehingga memunculkan gagasan dan fakta baru bahwa meningkatnya kesiapan digitalisasi UMKM juga ikut dipengaruhi oleh minat penggunaan teknologi seperti yang dihasilkan dari motivasi intrinsik individu menurut penelitian Caniëls, Lenaerts, \& Gelderman (2015) dan Suhandiah \& Ayuningtyas (2016). Penelitian ini memperkuat studi-studi sebelumnya tersebut bahwa meningkatnya motivasi intrinsik pengusaha akan meningkatkan minat penggunaan teknologi dan selanjutnya dapat meningkatkan kesiapan digitalisasi UMKM.

\section{Pengaruh Pengetahuan TIK terhadap Kesiapan Digitalisasi UMKM}

Berdasarkan hasil analisis statistik, pengetahuan TIK berpengaruh positif terhadap kesiapan digitalisasi UMKM kuliner di Kota Salatiga dengan tingkat kepercayaan $95 \%$. Hal tersebut ditunjukkan dengan nilai T statistik $\geq \mathrm{T}$ table $(1,968$ untuk tingkat kesalahan 5 persen two-tailed) dan nilai $P$ value $\leq 0,05$. Nilai original sampel pada hubungan variabel pengetahuan TIK dan variabel kesiapan digitalisasi menunjukkan nilai 0,796 , sehingga berdasarkan hasil uji di atas menunjukkan bahwa hipotesis tentang pengetahuan TIK berpengaruh positif terhadap kesiapan digitalisasi UMKM kuliner di Kota Salatiga, terdukung dalam penelitian ini.

Hasil penelitian ini menunjukkan bahwa pengetahuan TIK berpengaruh langsung terhadap kesiapan digitalisasi UMKM kuliner di Kota Salatiga. Artinya bahwa setiap kenaikan variabel pengetahuan TIK sebesar satu kali, maka kesiapan digitalisasi UMKM di Kota Salatiga akan meningkat sebesar 79,6 persen. Pengaruh positif yang cukup besar muncul dikarenakan kesiapan digitalisasi UMKM memiliki hubungan yang sangat erat dengan pengetahuan TIK pemilik UMKM. Semakin besar pengetahuan TIK pemilik UMKM, maka semakin mudah dan efisien pemilik UMKM untuk menggunakan teknologi (seperti smartphone dan PC/laptop). Apabila pemilik UMKM mampu dalam menggunakan teknologi tersebut maka kesiapannya untuk digitalisasi akan semakin besar.

Tabel 5. $R$ square

\begin{tabular}{lrr}
\hline & R-Square & $\begin{array}{l}\text { R-Square } \\
\text { Adjusted }\end{array}$ \\
\hline $\begin{array}{l}\text { Y1-Kesiapan } \\
\text { Digitalisasi }\end{array}$ &, 692 &, 650 \\
\hline
\end{tabular}


Dari pernyataan-pernyataan tersebut, hasil penelitian ini mendukung hasil penelitian terdahulu yaitu penelitian yang dilakukan oleh Okundaye, Fan, \& Dwyer (2019) dan Nair, Chellasamy, \& Singh (2019) bahwa pengetahuan TIK berpengaruh terhadap adopsi teknologi pada UMKM di negara berkembang. Meningkatnya pengetahuan TIK berakibat pada meningkatnya kesiapan digitalisasi UMKM.

Peranan Gender, Tingkat Pendidikan, dan Usia sebagai Variabel Pemoderasi

Pengaruh variabel pemoderasi terhadap hubungan motivasi intrinsik dan pengetahuan TIK dengan kesiapan digitalisasi UMKM dapat dilihat pada tabel analisis jalur bagian efek moderasi yaitu moderating effect 1 hingga moderating effect 6 . Berdasarkan tabel tersebut diketahui bahwa variabel moderating effect 1 hingga moderating effect 6 , tidak memenuhi syarat $\mathrm{T}$ tabel maupun $P$-value 0,05 atau 0,10 sehingga hipotesis variabel pemoderasi mampu memoderasi hubungan antara variabel motivasi intrinsik dan pengetahuan TIK dengan variabel kesiapan digitalisasi UMKM ditolak. Hal tersebut menunjukkan bahwa variabel pemoderasi yaitu usia, tingkat pendidikan, dan gender secara langsung tidak mempengaruhi hubungan motivasi intrinsik dan pengetahuan TIK terhadap kesiapan digitalisasi. Yang mana artinya pengambilan keputusan/pendapat pemilik UMKM yang berbeda gender, usia dan tingkat pendidikan memiliki kemiripan (tidak terlalu berbeda secara signifikan).

\section{Kesimpulan dan Saran}

\section{Kesimpulan}

Berdasarkan hasil penelitian dan analisis di atas dapat disimpulkan beberapa hasil penelitian. Pertama, motivasi intrinsik terbukti berpengaruh positif terhadap kesiapan digitalisasi UMKM kuliner di Kota Salatiga. Hal ini dikarenakan adanya dorongan dari dalam diri pemilik UMKM kuliner di Kota Salatiga untuk terus maju dan mengembangkan bisnisnya mengikuti era teknologi masa kini. Kedua, pengetahuan TIK terbukti berpengaruh positif terhadap kesiapan digitalisasi UMKM kuliner di Kota Salatiga. Penyebabnya adalah pengetahuan
TIK merupakan dasar pengetahuan pemilik UMKM kuliner di Kota Salatiga untuk menggunakan teknologi dan menuju ke kesiapan digitalisasi. Sehingga hal tersebut mempunyai pengaruh yang besar untuk kesiapan digitalisasi UMKM di Kota Salatiga. Ketiga, faktor demografi yang meliputi tingkat pendidikan, usia dan gender tidak terbukti berperan sebagai pemoderasi pengaruh motivasi intrinsik terhadap kesiapan digitalisasi maupun pengetahuan TIK terhadap kesiapan digitalisasi UMKM di Kota Salatiga. Hal ini dikarenakan pengambilan keputusan/pendapat antara pemilik UMKM yang berbeda gender, usia, dan tingkat pendidikan memiliki kemiripan (tidak terlalu berbeda secara signifikan) sehingga pengaruh variabel pemoderasi menjadi tidak signifikan dalam penelitian ini.

\section{Saran}

Dari hasil penelitian ini ada beberapa saran yang diusulkan untuk dilakukan untuk meningkatkan tingkat kesiapan digitalisasi UMKM kuliner di Kota Salatiga. Saran yang pertama ditujukan untuk Dinas Koperasi dan UKM Kota Salatiga, bahwa untuk meningkatkan kesiapan digitalisasi pemilik UMKM kuliner, perlu diberikan penyuluhan dan penyuluhan yang diberikan harus lebih berfokus pada peningkatan pengetahuan TIK terlebih dahulu dan selanjutnya meningkatkan motivasi pemilik UMKM kuliner agar mau menerapkan dan menggunakan ilmunya untuk beradaptasi dalam era digitalisasi. Saran kedua yang ditujukan untuk pemilik UMKM kuliner di Kota Salatiga adalah untuk mempersiapkan diri dalam menuju era digitalisasi yang pasti akan datang. Diperlukan pengetahuan TIK yang memadai dan motivasi intrinsik yang tinggi untuk mau berkembang, sehingga sebaiknya para pemilik UMKM kuliner di Kota Salatiga terus meningkatkan pengetahuan TIK yang dimiliki serta mencari maupun merenungkan alasannya berada di bisnis ini untuk meningkatkan motivasi intrinsiknya agar mau berkembang.

\section{Keterbatasan Penelitian dan Saran untuk Penelitian Mendatang}

Penelitian ini memiliki beberapa keterbatasan. Jumlah sampel pada penelitian ini masih terbilang kurang. Pasalnya pandemi 
Covid-19 membatasi ruang lingkup peneliti untuk memperoleh sampel yang lebih banyak (sekitar 150). Dikarenakan kurangnya sampel penelitian, maka teknik analisis data kemudian menggunakan software SmartPLS yang mana hanya mampu menampung data hingga maksimal 100 sampel. Selanjutnya, teknik analisis data dengan SmartPLS belum membuktikan adanya pengaruh variabel pemoderasi (usia, gender, dan tingkat pendidikan) terhadap hubungan antar variabel dalam penelitian ini. Peneliti beranggapan bahwa dalam penelitian mendatang dapat menggunakan teknik analisis data yang berbeda (menggunakan SEM, dengan jumlah sampel melebihi 150).

Untuk penelitian mendatang, disarankan untuk menguji ulang model dengan menambah jumlah sampel dengan kuantitas yang jauh lebih banyak (lebih dari 150). Hal ini dilakukan agar dapat memperoleh data dan hasil penelitian yang lebih akurat. Peneliti juga menyarankan agar pada penelitian selanjutnya dapat meneliti mengenai pengaruh secara langsung antara gender dan usia terhadap kesiapan digitalisasi. Hal ini dikarenakan munculnya asumsi diluar hipotesis penelitian ini (yang muncul dari analisis statistik dan analisis jalur) bahwa usia dan gender secara literatur diduga berpengaruh secara langsung terhadap kesiapan digitalisasi. Selain itu, model penelitian ini juga bisa diuji pada kelompok UMKM yang berbeda selain kuliner.

\section{Daftar Referensi}

Caniëls, M. C. J., Lenaerts, H. K. L., \& Gelderman, C. J. (2015). Explaining the internet usage of smes: The impact of market orientation, behavioural norms, motivation and technology acceptance. Internet Research, 25(3), 358-377. https://doi.org/10.1108/IntR-12-20130266

Chotijah, U., \& Retrialisca, F. (2020). Analysis of Information Technology Readiness in Furniture Business in Indonesia. Indonesian Journal of Information Systems, 3(1), 14. https://doi.org/10.24002/ijis.v3i1.3470

Deloitte Access Economic. (2015). UKM Pemicu Kemajuan Indonesia. Deloitte
Access Economic.

Embi, M. A., \& Saili, S. (2013). Motivasi Perkhidmatan Awam. Kuala Lumpur: ITBM.

Harmawan, B. N. (2018). Hambatan UMKM "Go-Online." Retrieved October 25, 2020, from mkp.fisipol.ugm.ac.id website:

https://mkp.fisipol.ugm.ac.id/2018/11/21 /hambatan-umkm-go-online/

Jumadi, R., Fauziyah, N., Rahim, A. R., Bashori, M. S. A., Ayyubi, S. Al, F, G., \& Wusono, B. (2020). Sosialisasi Revolusi Industri 4.0 Sebagai Program Pemberdayaan Masyarakat Menghadapi Era Digitalisasi, Desa Kedungsumber Kecamatan Balongpanggang, Kabupaten Gresik. Journal of Community Service, 2(2), 275-285.

Katadata Insight Center. (2020). Digitalisasi, Strategi UMKM Selamat dari Krisis. Retrieved October 3, 2020, from katadata.co.id website: https://katadata.co.id/0/analisisdata/5f03 cf11e0198/digitalisasi-strategi-umkmselamat-dari-krisis

Linawati, L. (2014). Pengaruh Motivasi Kerja Intrinsik Dan Motivasi Kerja Ekstrinsik Terhadap Kinerja Karyawan (Studi Pada Pt. Angkasa Pura I Bandar Udara Internasional Ahmad Yani Semarang). Kinerja, 18(1), 81-89. https://doi.org/10.24002/kinerja.v18i1.5 19

Maulana, F. H., Hamid, D., \& Mayoan, Y. (2015). Pengaruh Motivasi Intrinsik, Motivasi Ekstrinsik Dan Komitmen Organsasi Terhadap Kinerja Karyawan Pada Bank Btn Kantor Cabang Malang. Jurnal Administrasi Bisnis S1 Universitas Brawijaya, 22(1), 85893.

Nair, J., Chellasamy, A., \& Singh, B. N. B. (2019). Readiness Factors for Information Technology Adoption in SMEs: Testing an Exploratory Model In an Indian Context. Journal of Asia Business Studies, 13(4), 694-718. https://doi.org/10.1108/JABS-09-20180254

Napitupulu, D., Syafrullah, M., Rahim, R., 
Abdullah, D., \& Setiawan, M. I. (2018). Analysis of User Readiness Toward ICT Usage at Small Medium Enterprise in South Tangerang. Journal of Physics: Conference Series, 1007(1). https://doi.org/10.1088/1742$6596 / 1007 / 1 / 012042$

Nasir, M. (2013). Evaluasi Penerimaan Teknologi Informasi Mahasiswa di Palembang Menggunakan Model UTAUT. Seminar Nasional Aplikasi Teknologi Informasi (SNATI), 1(1), 152013. Retrieved from https://journal.uii.ac.id/Snati/article/vie w/3006

Okundaye, K., Fan, S. K., \& Dwyer, R. J. (2019). Impact of information and communication technology in Nigerian small-to medium-sized enterprises. Journal of Economics, Finance and Administrative Science, 24(47), 29-46. https://doi.org/10.1108/JEFAS-08-20180086

Pamukti, U. M., Hartanto, R., \& Winarno, W. W. (2017). Analisis Kesiapan Individu Dalam Implementasi Manajemen Pengetahuan Di Instansi Pemerintah. Prosiding SNATI F, 4, 243-248.

Parasuraman, A., \& Colby, C. L. (2015). An Updated and Streamlined Technology Readiness Index: TRI 2.0. Journal of Service Research, 18(1), 59-74. https://doi.org/10.1177/1094670514539 730

Pramana, A. . N. D. W., \& Mandala, K. (2014). Pengaruh Usia Dalam Memoderasi Pengaruh Tingkat Kesiapan Teknologi Pada Niat Konsumen Dalam Menggunakan Layanan Sms Banking Di Kota Denpasar. 3274-3290.

Putra, A. K., \& Frianto, A. (2013). Pengaruh Motivasi Intrinsik dan Motivasi Ekstrinsik Terhadap Kepuasan Kerja. Jurnal Bisnis Dan Manajemen, 6(1), 5966.

Putri, A. S. (2020). Pengertian Teknologi Informasi dan Komunikasi (TIK) dan Contohnya. Retrieved November 13, 2020, from Kompas.com website: https://www.kompas.com/skola/read/20 20/09/10/194000969/pengertianteknologi-informasi-dan-komunikasitik-dan-contohnya?page $=$ all

Putri, K. (2018). Pengertian Teknologi Informasi, Serta Tujuan dan Fungsinya. Retrieved November 2, 2020, from teknologi.id website: https://teknologi.id/insight/pengertianteknologi-informasi-serta-tujuan-danfungsinya/

Riyanto, S., \& Hatmawan, A. A. (2020). Metode Riset Penelitian Kuantitaif: Penelitian di Bidang Manajemen, Teknik, Pendidikan dan Eksperimen (I). Yogyakarta: Deepublish.

Rusliati, E., \& Mulyaningrum, M. (2019). Pengembangan Manajemen Fungsional Melalui Program Digital Pada Usaha Mikro Dan Kecil di Majalengka. 2020, 127-134. https://doi.org/10.33510/slki.2019.127134

Santia, T. (2020). Berapa Jumlah UMKM di Indonesia? Ini Hitungannya. Retrieved October 25, 2020, from Liputan6.com website:

https://www.liputan6.com/bisnis/read/43 46352/berapa-jumlah-umkm-diindonesia-ini-

hitungannya\#: :text=Menurut Badan Pusat Statistik (BPS, usaha yang beroperasi di Indonesia

Sari, R. P., \& Santoso, D. T. (2019). Pengembangan Model Kesiapan UMKM di Era Revolusi Industri 4.0. Jurnal Media Teknik \& Sistem Industri, 3(1), 37-42. Retrieved from http://jurnal.unsur.ac.id/index.php/JMTS

Sari, Y. K. P. (2018). Perkembangan Teknologi Informasi "Tradisi Media Lisan, Cetak, Era First Age Media, Second Age Media, Era Digital." Retrieved November 18, 2020, from binus.ac.id website: https://binus.ac.id/malang/2018/07/perke mbangan-teknologi-informasi-tradisimedia-lisan-cetak-era-first-age-mediasecond-age-media-era-digital/

Sekaran, U., \& Bougie, R. (2016). Research 
Methods for Business: A Skill-Building Approach. In Wiley (7th ed.). Chichester: John Wiley \& Sons.

Septikhtiarif, F., \& Handayaningsih, S. (2017). Pengukuran E-Readiness Menggunakan Framework Stope Pada Proses Pengajuan Cuti Akademik Perguruan Tinggi. Prosiding Annual Research Seminar 2017Computer Science and ICT, 3(1), 173-177.

Slamet, R., Nainggolan, B., Roessobiyatno, R., Ramdani, H., Hendriyanto, A., \& Ilma, L. L. (2017). Strategi Pengembangan UKM Digital Dalam Menghadapi Era Pasar Bebas. Jurnal Manajemen Indonesia, 16(2), 136. https://doi.org/10.25124/jmi.v16i2.319

Sofyani, H. (2016). Modul Praktik Partial Least Square ( PLS ): Untuk penelitian Akuntansi. Yogyakarta: Universitas Muhammdiyah Yogyakarta.

Sonora.id. (2019). Motivasi Intrinsik dan Ekstrinsik, Mana yang Lebih Penting untuk Penunjang Karier? Retrieved November 2, 2020, from www.sonora.id website:

https://www.sonora.id/read/421840531/ motivasi-intrinsik-dan-ekstrinsik-manayang-lebih-penting-untuk-penunjangkarier?page $=$ all

Suhandiah, S., \& Ayuningtyas. (2016).
Pengaruh Motivasi Pada Akseptabilitas Brilian Menggunakan Utaut Model. Jurnal Komunikasi, Media Dan Informatika, 5(3), 132-142.

Syarifah, I., Mawardi, M. K., \& Iqbal, M. (2020). Pengaruh modal manusia terhadap orientasi pasar dan kinerja UMKM. Jurnal Ekonomi Dan Bisnis, 23(1), 69-96. https://doi.org/10.24914/jeb.v23i1.2521

Talebian, S., Mohammadi, H. M., \& Rezvanfar, A. (2014). Information and Communication Technology (ICT) in Higher Education: Advantages, Disadvantages, Conveniences and Limitations of Applying E-learning to Agricultural Students in Iran. Procedia Social and Behavioral Sciences, 152, 300-305.

https://doi.org/10.1016/j.sbspro.2014.09. 199

Widiastuti, S., \& Budi, I. (2016). Analisis Pengukuran Tingkat Kesiapan Knowledge Management: Studi Kasus Pusat Pengolahan Data dan Informasi Badan Koordinasi Penanaman Modal. Seminar Nasional Aplikasi Teknologi Informasi (SNATi), 22-29.

Zhang, L., Nyheim, P., \& Mattila, A. S. (2017). The effect of power and gender on technology acceptance. The Eletronic Library, 34(1), 1-5. 